\title{
Capítulo
}

4

\section{Educação a Distância: a construção de competências docentes}

\author{
Patricia Alejandra Behar, Maira Bernardi e Sandra Andrea Assumpção \\ Maria
}

\begin{abstract}
The Distance Education is a modality that over the years takes outstanding locations, especially regarding the construction of innovative and inclusive teaching practices. In this process, teacher education that strives to develop the, learning to know, learning to do and learning to be of utmost importance to be able to develop the subject at all levels, both personal and social, and cultural. Therefore, this work aims to discuss the development and / or the improvement of teaching skills in order to enable the construction of learning strategies and the implementation of educational planning in different contexts and audiences in Distance Education.
\end{abstract}

\section{Resumo}

A Educação a Distância é uma modalidade que no decorrer dos anos ocupa espaços de destaque, principalmente no que tange a construção de práticas pedagógicas inovadoras e inclusivas. Neste processo, uma formação docente que prima por desenvolver o saber, saber fazer e saber ser é de extrema importância para que seja possivel desenvolver o sujeito em todas as esferas, tanto pessoal, como social e cultural. Portanto, este texto visa discutir o desenvolvimento elou aprimoramento de competências docentes a fim de possibilitar a construção de estratégias de aprendizagem e a aplicação do planejamento pedagógico em diferentes contextos e públicos na Educação a Distância.

\subsection{Introdução}

Este texto visa abordar sobre o contexto atual da Educação a Distância (EAD), especialmente no que se refere às competências docentes nessa modalidade de educação. Este panorama tem o propósito de iniciar a discussão mais aprofundada do tema sobre competências, competências na EAD e finalmente as competências docentes para atuar e desempenhar seu papel de modo inovador e inclusivo. 
Em termos educacionais, [Perrenoud 2000] iniciou discussões sobre como trabalhar com competências na educação. Em 2002, o mesmo autor lança o livro "As competências para ensinar no século XXI" onde retoma o panorama das mudanças decorrentes do avanço tecnológico e quais seriam as ações necessárias para enfrentá-las. [Zabala e Arnau 2009], também discutem sobre o mesmo tema na educação.

Do mesmo modo, [Behar et al 2013] apresenta conceitos sobre a temática e define três elementos como sendo fundamentais para a construção da competência pelo indivíduo. Ainda sob esse prisma, destaca que é necessário mobilizar alguns recursos em conjunto com os elementos da competência a fim de possibilitar a base e a propulsão para que as mesmas possam se estabelecer.

Na primeira seção o termo Competências é abordado considerando o contexto da Educação a Distância. Nesta perspectivas são ressaltadas as concepções defendidas por [Perrenoud 2001], [Zabala e Aunau 2010] e [Behar et al. 2013].

Na seção seguinte é abordado o tema Competência Docentes. Este acena para o desenvolvimento de competências específicas para possibilitar ao professor a construção de estratégias inclusivas e inovadoras. O tema é discutido e fundamentado teoricamente em [Freire 1996], [Paquay e Wagner 2001] e [Coronado 2009]. No final dessa seção é apresentado um levantamento dos Conhecimentos, Habilidades e Atitudes (CHA) especificamente das Competências Docentes em EAD.

Por fim, a última seção tem por propósito apresentar possíveis usos de ferramentas e recursos digitais nas práticas pedagógicas na $\mathrm{EAD}$, considerando as competências docentes para a EAD e as características da própria modalidade.

\subsection{Competências na Educação a Distância}

Há muito tempo, as instituições de ensino organizam-se como se os objetivos da educação fossem obtidos a partir do desenvolvimento das diversas disciplinas científicas no intuito de adquirir o conhecimento científico e assim garantir uma educação formal.

Atualmente, discute-se que o objetivo principal da educação não está somente em ensinar os conteúdos curriculares, mas também no desenvolvimento de competências. Abstrair apenas o conhecimento científico não é mais suficiente, pois espera-se que o indivíduo possa se preparar para enfrentar situações-problema com as quais se depara no dia-a-dia.

Sob essa perspectiva, percebe-se a necessidade de uma reorganização escolar no que se refere ao tempo e ao espaço a partir da inter-relação da ciência e as competências. O termo competências surgiu para designar uma pessoa capaz de realizar, de forma eficiente, uma determinada tarefa e, desde então, é utilizada como referência em diferentes segmentos para a formação pessoal, acadêmica e profissional [Perrenoud et al. 2002].

Diante deste cenário, o papel do professor também precisa ser aprimorado uma vez que a construção do conhecimento e os valores encontram-se essencialmente interrelacionados.

Nesse sentido, não se propõe terminar com a organização de disciplinas, mas rever como esses conteúdos estão sendo trabalhados pelos professores de modo a favorecer o desenvolvimento de competências em suas diferentes esferas. 
[Perrenoud et al. 2002] enfatiza que

[...] a formação escolar deve prover as pessoas de competências básicas, como a capacidade de expressão, de compreensão do que se lê, de interpretação de representações; a capacidade de mobilização de esquemas de ação progressivamente mais complexos e significativos nos mais diferentes contextos; a capacidade de construção de mapas de relevância das informações disponíveis, tendo em vista a tomada de decisões, a solução de problemas ou o alcance de objetivos previamente traçados; a capacidade de colaborar, de trabalhar em equipe e, sobretudo, a capacidade de projetar o novo, de criar em um cenário de problemas, valores e circunstâncias na qual somos lançados e no qual devemos agir solidariamente.

Para isso, o professor precisa considerar o projeto pedagógico da escola, pois este vai detalhar a epistemologia que está imbricada e o tipo de individuo que se pretende formar.

A formação do indivíduo deve contemplar uma verdadeira preparação para o mundo, preparando-o para construir competências ao longo da vida, aprendendo como fazer uso delas na prática, na vivência do dia a dia. Torna-se necessário refletir sobre o panorama em que apenas um ensina e os demais aprendem, no sentido em que não se deve oferecer ao aluno um conhecimento pronto e acabado. É imperativo que o professor saiba ajudá-lo na busca da melhor forma de construir seu conhecimento.

Para isso, o professor necessitará mobilizar conhecimentos prévios e construir novos conhecimentos para desenvolver as competências necessárias à sua prática educativa e, assim, favorecer a elaboração de estratégias educacionais para que propicie aos seus alunos o pleno desfrute de suas potencialidades. $\mathrm{O}$ seu processo de formação será eterno, uma vez que necessita refletir sobre seus próprios processos. Sendo assim, torna-se necessário definir o termo competência. O que é competência?

Segundo [Zabala e Arnau 2010] a competência se refere à capacidade ou à habilidade para realizar tarefas ou atuar frente a situações diversas de forma eficaz em um determinado contexto. É necessário mobilizar atitudes, habilidades e conhecimentos ao mesmo tempo e de forma inter-relacionada.

Para [Perrenoud et al. 2002, p. 164] competência significa

[...] a capacidade de compreender uma determinada situação e reagir adequadamente frente a ela, ou seja, estabelecendo uma avaliação dessa situação de forma proporcionalmente justa para com a necessidade que ela sugerir a fim de atuar da melhor maneira possível.

O autor ainda complementa que a competência pressupõe a existência de elementos: Conhecimentos, Habilidades e Atitudes, sintetizados pela sigla CHA. Tais elementos são estruturados em um contexto determinado com o intuito de solucionar um problema, lidar com uma situação nova.

O Conhecimento, segundo [Perrenoud 2001, p.18] é o elemento que corresponde ao saber do sujeito em relação a uma determinada competência.

Para mim, saberes e conhecimentos são representações organizadas do real, que utilizam conceitos ou imagens mentais para descrever e, eventualmente, explicar, às vezes antecipar ou controlar, de maneira mais ou menos formalizada e estruturada, fenômenos, estados, processos, mecanismos observados na realidade ou inferidos a partir da observação. 
[Behar et al 2013] define Habilidade como sendo uma ação automatizada, um procedimento já construído, algo da ordem do operacional, não exigindo se deter em uma reflexão mais aprofundada. Refere-se ao colocar em prática, em saber fazer.

[Rodrigues 1994] define as Atitudes como um conjunto de crenças, sentimentos e tendências comportamentais dos sujeitos frente a um determinado objeto social. Está relacionada às intenções, ao desejo e as vontades do indivíduo.

[Behar et al. 2013] ainda ressalta que existem os recursos de suporte (biofisiológico), evolução (criatividade) e mobilização (afetividade) que colocam em ação e perpassa os elementos do CHA. Esses recursos servem de suporte e propulsão para potencializar o desenvolvimento das competências.

O biofisiológico refere-se a tudo que diz respeito ao corpo, isto é, todas as funções biológicas e fisiológicas. O recurso de criatividade infere uma ação original, na direção da construção de algo novo para o sujeito. Por fim, o recurso de afetividade é a fonte de energia que a cognição utiliza para seu funcionamento, que impulsiona as ações. Nesse sentido, a Figura 4.1 apresenta as relações que os elementos da competência e seus recursos estabelecem sobre o indivíduo visando prepará-lo para a vida.

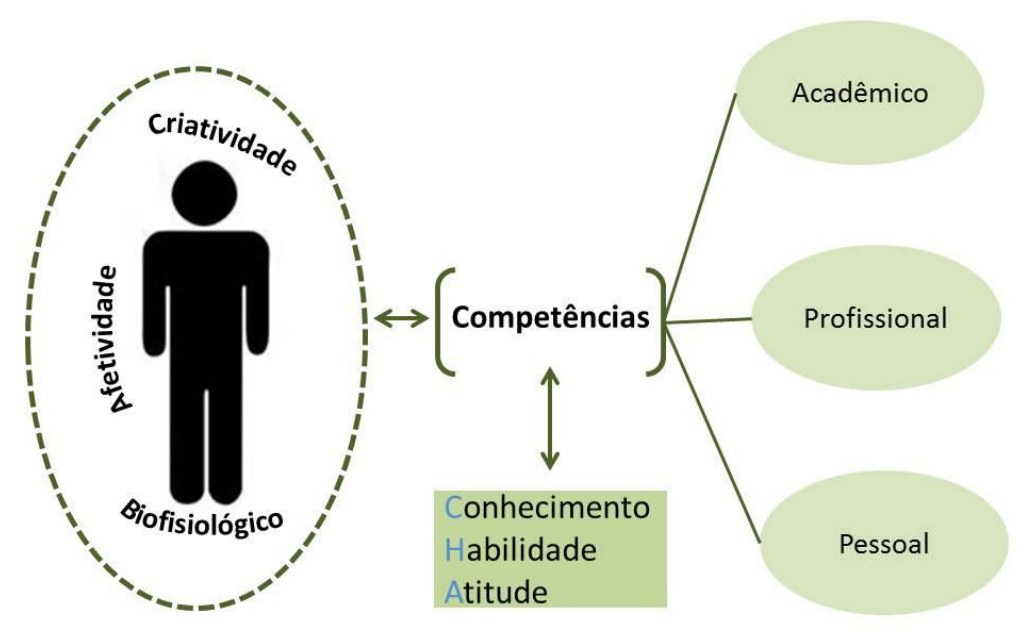

Figura 4.1. Competências e o indivíduo

Além da importância do desenvolvimento de competências, conforme mencionado anteriormente e considerando o indivíduo em todas as suas formas de atuar na vida (acadêmico, profissional e pessoal), observou-se que na EAD também haveria a necessidade de construir/aprimorar determinadas competências [Zabala e Arnau 2010].

Em especial, os atores da EAD também precisam possuir competências para atuar nessa modalidade. [Zabala e Arnau 2010] relata que conhecer as características e os componentes de cada competência nos permite extrair a informação que nos facilita a formulação de possíveis estratégias de ensino e aprendizagem pelos docentes.

Sendo assim, busca-se indicar que para a sua atuação, o professor deverá considerar as particularidades da modalidade (separação física/espaço entre professor e aluno, possibilidade de diferentes formas de comunicação, flexibilidade do tempo, uso das tecnologias digitais, etc.), uma vez que os processos de ensino e de aprendizagem possuem uma dinâmica diferenciada de trabalho. 
A prática pedagógica envolve inúmeros aspectos, entre eles a realização de atividades em tempos e espaços diversos e a utilização das tecnologias digitais. Sendo assim, a próxima seção irá tratar, primeiramente, sobre as competências docentes em linhas gerais e, a seguir, apresentar um mapeamento acerca das características específicas da modalidade de EAD.

\subsection{Competências Docentes}

Esta seção refere-se às competências docentes para o desenvolvimento de estratégias inclusivas e inovadoras. Sabe-se que a EAD perpassa por diferentes mudanças, a priori estão sendo redefinidos os papeis dos seus atores: alunos, gestores e professores [Palloff e Pratt, 2004].

Partindo deste panorama, o docente na EAD precisa aprimorar e desenvolver diversas competências essenciais para a suas práticas pedagógicas. Diante deste cenário, torna-se importante discutir sobre algumas competências docentes básicas do docente, independente da modalidade de ensino, para depois buscar uma definição das competências voltadas para a modalidade a distância.

Primeiramente, são referenciados os escritos de autores como [Freire 1996], [Paquay e Wagner 2001], e [Coronado 2009] que trazem importantes apontamentos para fundamentar a reflexão acerca das principais competências dos professores. $\mathrm{Na}$ sequência apresenta-se uma sistematização das competências docentes para a EAD.

Ao remeter à definição de [Perrenoud 2001], pode-se perceber a relação existente entre competência e saberes. Como é comentado pelo autor, a concepção de competência está relacionada com as práticas do cotidiano, ou seja, situações em que seja necessário tomar decisões e resolver problemas. E por isso trata-se de mobilizar os diferentes saberes.

\subsubsection{A perspectiva de Paulo Freire: a relação entre competência e saberes}

Encontra-se no estudo delineado por [Freire 1996], presente no livro "Pedagogia da Autonomia", a abordagem da temática da formação docente promovida pela reflexão sobre a prática educativo-progressiva em favor da autonomia do ser dos educandos.

Nesta obra, [Freire 1996, p.25] concorda que quem ensina aprende ao ensinar e quem aprende ensina ao aprender, pois "não há docência sem discência". Assim, durante sua exposição, [Freire 1996] esclarece que há saberes fundamentais que devem ser aprendidos para qualquer atividade a ser exercida, e a importância de se ter uma reflexão crítica sobre a prática na relação que esta estabelece com a teoria. Desta forma, serão apresentados alguns desses saberes, considerados indispensáveis à prática educativa progressista, os conteúdos a serem assumidos para uma organização da formação docente, que devem ser facilmente compreendidos.

(1) Ensinar exige a criação de possibilidades para a produção ou construção de conhecimentos [Freire 1996, p.25], partindo do entendimento que o ato de ensinar depende da existência da aprendizagem e vice-versa.

Segundo [Freire 1996, p.25], "aprender precedeu ensinar ou, em outras palavras, ensinar se diluía na experiência realmente fundante de aprender". O autor enfatiza a importância de considerar o processo de ensinar-aprender como atitude política, que 
deve apontar uma direção a ser seguida, ao invés de cair na neutralidade, embargada de ética para ser decente e comprometida com a transformação social.

$\mathrm{Na}$ sua concepção, ensinar é o processo responsável por despertar no aluno a curiosidade, o gosto por aprender mais, sendo cada vez mais um criador crítico. [Freire 1996] ainda lembra que uma das tarefas principais do educador democrático é dar condições para que o aluno estenda sua capacidade crítica, colocando-o mais próximo das coisas a serem conhecidas, ao invés de simplesmente memorizá-las. De acordo com o autor, o educando que interage com o educador, também é sujeito de construção e reconstrução do processo educativo. Ao trabalhar com determinado objeto, aprende a sua essência, o porquê de ser assim e o seu efeito no mundo. Neste sentido, tudo deve ser relacionado com a realidade, analisando sua interferência.

(2) Ensinar exige rigorosidade metódica, destacando a necessidade de reforçar a criticidade e a criatividade dos alunos, transformando-os em sujeitos da construção e reconstrução do saber.

[Freire 1996] alerta que a educação bancária, presente nas escolas, vem distorcendo o conceito de ensinar, liquidando com a criatividade, colocando o professor sobre o aluno, numa atitude autoritária.

De acordo com o autor, a reversão dessa situação depende de manter o educando consciente e com vontade de criar, de arriscar e aventurar-se para combater essa educação imobilizadora. Voltando-se contra ela com sua curiosidade e vontade de aprender, é possível, segundo [Freire 1996], construir uma sociedade na qual a educação não seja passiva, mas elemento problematizador, de dúvida, de um constante construir e reconstruir.

(3) Ensinar exige pesquisa, busca, indagação, constatação e intervenção. Só assim é possível perceber-se um sujeito pesquisador.

O autor também problematiza o papel do professor enquanto pesquisador. Para [Freire 1996], todo professor deve ser um pesquisador, de modo a estar sempre atualizado, acompanhando os acontecimentos no mundo e suas reflexões sobre a vida dos indivíduos. Nesta perspectiva, o ato de pesquisar surge das dúvidas, da necessidade de constatar fatos, de intervir no mundo. Segundo [Freire 1996], quem pesquisa pensa certo, tem rigorosidade metódica, ultrapassando a ingenuidade. Para ele, pensar certo é respeitar as opiniões contrárias, o ponto de vista dos educandos ainda que permaneçam no senso comum. A ação do professor deve ser direcionada para a constituição da conscientização crítica e comprometida com a mudança, necessária para o fím da ingenuidade, concretizando uma sociedade de iguais.

(4) Ensinar exige respeito aos saberes dos educandos, partindo da discussão sobre a realidade concreta, dos saberes socialmente construídos por eles e sua relação ao ensino dos conteúdos.

Assim, o pensar certo também coloca ao professor a necessidade de considerar os saberes que seus alunos trazem do seu cotidiano, da vida concreta que acontece fora da escola, para serem relacionados ao ensino dos conteúdos propostos pelo processo educativo, os quais devem ser considerados e repensados, para terem significação na vida das pessoas. 
(5) Ensinar exige criticidade, superação da curiosidade ingênua que se criticiza, transformando-se em curiosidade inquieta e indagadora.

A criticidade é considerada por [Freire 1996] como a superação da consciência ingênua que vai se tornando mais crítica, mais rigorosa frente os fatos. Para o autor, é na medida em que a curiosidade ingênua (do senso comum) vai se criticizando, tomando com mais severidade a relação com o objeto a ser desvendado, que esta tornase curiosidade epistemológica. Epistemológica porque é indagadora, investigadora, dos conhecimentos a serem apreendidos criticamente. A curiosidade humana assim precisa ser para não cair na docilidade, na neutralidade. [Freire 1996] declara não ser contrário ao avanço e uso da tecnologia desde que esta seja utilizada a favor do desenvolvimento da curiosidade crítica e da transformação da sociedade, em favor da "boniteza da vida".

(6) Ensinar exige estética e ética, no sentido que exercício do trabalho docente que é a favor da luta em defesa da verdade exige também o preparo científico.

Neste momento, [Freire 1996] chama aos professores a necessidade de ter ética no exercício de seu trabalho, lutando para que a verdade triunfe nas relações entre educadores e educandos. Deste modo, há de salientar a importância do preparo científico dos docentes para trabalharem com ética, serem coerentes com os fatos e com os outros, respeitando suas opiniões, sejam elas diferentes ou não das suas. É antes de mais nada ter humildade suficiente para assumir que também tem muito para aprender.

\section{(7) Ensinar exige Bom senso}

[Freire 1996] define a necessidade de ter bom senso de várias maneiras. Uma delas é usar a autoridade para tomar decisões, dar diretividade a seu trabalho ao estabelecer tarefas e metas a serem seguidas. Entretanto, é necessário também ter humildade em rever qualquer atitude tomada que não esteja sendo realizada de forma eficaz. Para o autor ter bom sendo também está relacionado em ser favorável a cientificidade dos fatos para não serem meras observações vazias e irrevogáveis, usando assim, a capacidade investigadora, indagadora e até mesmo duvidosa sempre a favor da transformação democrática da sociedade.

(8) Ensinar exige a corporeificação das palavras pelo exemplo, na medida em que pensar certo é fazer certo.

Para [Freire 1996, p.38], "quem pensa certo está cansado de saber que as palavras a que falta a corporeidade do exemplo pouco ou quase nada valem. Pensar certo é fazer certo". Neste sentido, a palavra sem exemplificação é vazia de sentido. Isto significa, como observa o autor, ler livros e mais livros sem relacioná-los, adentrá-los, descobrir a sua essência, concordar ou não com eles. Quem simplesmente memoriza, pensa errado, engana-se ao pensar que sabe algo que logo se perderá. E, infelizmente esta tem sido uma prática recorrente nas escolas que pregam uma educação desconectada do real, vazia de significação.

(9) Ensinar exige risco, aceitação do novo e rejeição a qualquer forma de discriminação. Faz parte do pensar certo a disponibilidade ao risco, aceitar o velho pela sua validade e o novo pela sua inovação. Da mesma forma, pensar certo pressupõe negar todo tipo de preconceito e discriminação. 
Novamente [Freire 1996] volta a tratar da rejeição da discriminação, do pensar certo. Ele alerta que pensar certo é uma tarefa dolorosa já que necessita de um constante cuidado para evitar deslizes e cair na incoerência ou na raiva desmedida. Mas não significa que há regras a serem seguidas. Simplesmente é preciso ética e rigorosidade metódica, estar bem definido o que se quer e aonde se pretende chegar.

(10) Ensinar exige o reconhecimento e a assunção da identidade cultural.

Segundo [Freire 1996], é preciso assumir-se como ser pensante, comunicante, transformador, criador, realizador de sonhos - com sentimentos que vão da raiva ao amor.

Através dos saberes destacados por [Freire 1996], percebe-se que a ação docente tem seu momento fundamental quando oportuniza um movimento dinâmico e dialético. É este movimento entre o "fazer e o pensar sobre o fazer" que possibilita o exercício de reflexão consciente e crítica sobre a sua prática profissional. Ainda segundo [Freire 1996, p.43-4] "é pensando criticamente a prática de hoje ou de ontem que se pode melhorar a próxima prática".

\subsubsection{A abordagem de Paquay e Wagner: tipos de professores e competências}

Já o foco da abordagem de [Paquay e Wagner 2001, p.136] está na formação inicial do professor. Segundo os autores, o termo competência é composto pela aquisição de todas as ordens de saberes (saber-fazer, saber-ser e saber-tornar-se) voltados para a realização de uma determinada tarefa ou resolução de problemas. Para eles, o estabelecimento das competências está diretamente relacionado com os paradigmas da docência (comportamental, artesanal, crítico e personalista). Estes são interpretados como "núcleos de princípios e hipóteses fundamentais que determinam tal ou qual modo de abordagem de uma realidade" [Paquay e Wagner 2001, p.135].

Para o paradigma comportamental, a essência está na separação de teoria e prática. No paradigma artesanal, a prática do ensino é comparada ao professor como bricoleur, ou seja, enfatiza-se o desenvolvimento de saberes e competências na sua aplicação no contexto através da prática, em uma reflexão da ação. Já no paradigma crítico, o ensino é pautado na pesquisa e em um conjunto de atitudes, de processos investigativos que visam o exercício da análise, da reflexão e do estabelecimento da criticidade. O paradigma colaborativo pressupõe as relações de troca, de intervenção e de aprendizagem desenvolvidas de forma colaborativa. E, por último, o paradigma personalista, no qual o ensino é considerado como um processo de desenvolvimento pessoal a partir de princípios e de inter-relações singulares, e do desenvolvimento profissional dos professores [Paquay e Wagner 2001; Paquay 2004].

Neste sentido, [Paquay e Wagner 2001] consideram o professor como profissional do ensino e por isso elaboram e defendem um referencial de competências profissionais do professor:

(1) Professor "culto" ou mestre instruído: é caracterizado por aquele que domina e privilegia os diferentes saberes teóricos (disciplinares e interdisciplinares, didáticos e epistemológicos, pedagógicos, psicológicos e filosóficos), ocorrendo, assim, a sobrevalorização dos conhecimentos acadêmicos e da formação teórica. A ação principal do professor é a transmissão desses saberes. 
(2) Professor "técnico": enfatiza o saber-fazer técnico e a aplicação das regras. O trabalho docente é pautada na utilização de técnicas de ensino e de atividades de microensino clássico.

(3) Professor "prático artesão": domina os saberes da prática, ou seja, a construção dos conhecimentos se dá de forma exclusiva por meio da prática, muitas vezes não acompanhada de uma ação reflexiva. Desta forma, a prática docente acaba por apoiar-se em rotinas e esquemas de ação contextualizados e na automatização dos saberes práticos.

(4) Professor "prático reflexivo": tem sua prática pautada em um saber da experiência através de uma reflexão sobre a prática e sua comunicação. Para isso promove atividades de prática com objetivo de analisar seus efeitos, produzindo, assim ferramentas inovadoras para tornar-se um professor pesquisador.

(5) Professor como "ator social", aquele que conhece e se envolve com situações na escola além da sala de aula, participa de projetos coletivos, conhece o contexto escolar e os problemas sociais em que a comunidade escolar está inserida; O professor como ator social analisa os desafios sociais das situações cotidianas e envolve-se em projetos coletivos. A importância dos estágios em campo na formação acontecem como uma oportunidade de envolvimento em um ofício coletivo.

(6) Professor como "pessoa", que possibilita a construção de uma identidade docente por meio do desenvolvimento pessoal e relacional, experimentando no estágio novas maneiras de interagir com os alunos e com os colegas, entre outros aspectos. O professor como pessoa está em desenvolvimento pessoal, na formação profissional busca relacionar-se e comunicar-se com o outro.

A partir dos perfis e competências profissionais destacados por [Paquay e Wagner 2001], compreende-se que os autores não indicam a adoção de uma ou outra concepção de formação de professor para orientar o curso de forma prioritária. A seguir pode ser visualizada na Tabela 4.1 a relação existente entre as competências dos professores profissionais, seus saberes e paradigmas.

Tabela 4.1. Relação entre as competências dos professores profissionais, saberes e Paradigmas - Adaptado [Paquay e Wagner 2001]

\begin{tabular}{|l|l|l|l|l|l|l|}
\hline Professor & Culto & Técnico & Artesão & $\begin{array}{l}\text { Prático } \\
\text { Reflexivo }\end{array}$ & Ator Social & Pessoa \\
\hline Saber & Saber & Fazer Técnico & Prático & Experiência & Empenho & $\begin{array}{l}\text { Ser e Tornar- } \\
\text { se }\end{array}$ \\
\hline Paradigma & $\begin{array}{l}\text { de } \\
\text { Controle }\end{array}$ & Comportamental & Artesanal & Crítico & Colaborativo & Personalista \\
\hline
\end{tabular}

De acordo com os autores, pode-se observar a complementaridade existente entre os modelos destacados. O conjunto desses contempla, assim, a diversidade de dimensões da prática docente. Desta forma, o professor que se torna um profissional do ensino precisa ter o domínio dos saberes a ensinar, a fim de promover a reflexão sobre os saberes interdisciplinares, visando a compreensão da sociedade complexa, em mudança e em interação [Paquay e Wagner 2001].

\subsubsection{Estudo de Coronado: competências docentes}

No trabalho de [Coronado 2009], também é encontrada uma produção relevante para o debate acerca das competências docentes. De acordo com a autora a competência é 
considerada como um "conjunto de integrado e dinâmico de saberes, habilidades, capacidades e destrezas, atitudes e valores postos em jogo em uma tomada de decisões, na ação e no desempenho concreto do sujeito em um determinado espaço profissional" [Coronado 2009, p.19].

Neste sentido, o conceito de competência apresentado enfatiza a interação e articulação de diversas ordens de saberes em contextos que se modificam. Dentre eles, podem ser citados o saber ser, o querer ser, o poder ser e o ser, que articulam-se em uma construção de competência. Nesta perspectiva defendida pela autora, a atuação competente evidencia um saber reflexivo e contextualizado constituído em um espaço pautado e estruturado.

Como tal, a competência implica em um conjunto complexo e integrado de conhecimentos, habilidades e destrezas, valores e atitudes, que dotam o indivíduo da capacidade, com um saber ser e saber estar. Desta forma, parte-se do entendimento que a "competência é uma construção subjetiva, individual e, portanto, intransferível" [Coronado 2009, p.25-6].

Nesta perspectiva, [Coronado 2009] faz um recorte sobre as competências específicas didático-pedagógicas organizando-as da seguinte forma:

(1) Programar: implica definir e estruturar um programa de análise que esteja de acordo com o currículo, regulamento da instituição e perfil dos estudantes.

(2) Planificar: envolve o desenvolvimento de um plano de trabalho anual/semestral para o espaço curricular, de forma que contemple tempos, recursos, atividades e conduza a níveis de avaliação e recuperação.

(3) Produzir atividades e material didático-pedagógico: requer o design de atividades, ambientes e materiais de instrução conforme critérios de relevância, congruência e funcionalidade.

(4) Conduzir o processo de ensino e aprendizagem: supõe o desenvolvimento de um roteiro de classe que estabeleça a dinâmica de trabalho e do ambiente de aprendizagem selecionado. Esta competência também diz respeito a analisar e avaliar de forma crítica e reflexiva o próprio desempenho.

(5) Avaliar: remete ao design e planejamento de instâncias, ambientes e instrumentos de avaliação que permitam coletar evidências de conhecimento e desempenho, conforme os critérios de objetividade, transparência e flexibilidade. Esta competência implica também oferecer retroalimentação ou feedback aos alunos.

Com base nos autores destacados, percebe-se a íntima relação entre os saberes e as competências. Esta relação íntima torna-se ainda mais pontual ao se tratar do trabalho docente. Com a introdução das tecnologias nas salas de aula, o maior desafio está, exatamente, na mobilização de saberes e de competências, tendo como premissa, congregar tais tecnologias ao processo pedagógico. Ressalta-se, assim, a importância da formação de professores (seja ou não continuada) ir além da apresentação teórica expositiva, promovendo atividades que vislumbrem uma orientação prático-reflexiva, somadas ao suporte das TIC. De acordo com [Nevado et al. 2007, p.86], "com o intenso fluxo de informações e mudanças que configuram a instabilidade dos saberes, os professores precisarão cada vez mais enriquecer constantemente as competências, diminuindo as demarcações entre o período de formação e o período profissional". 


\subsubsection{Competências Docentes em EAD}

Analisando as considerações até então abordadas, busca-se estabelecer um levantamento dos Conhecimentos, Habilidades e Atitudes (CHA) relacionados à ação didática e pedagógica do professor na EAD a partir do levantamento proposto por [Bernardi et al. 2013] apresentado na Figura 4.2.

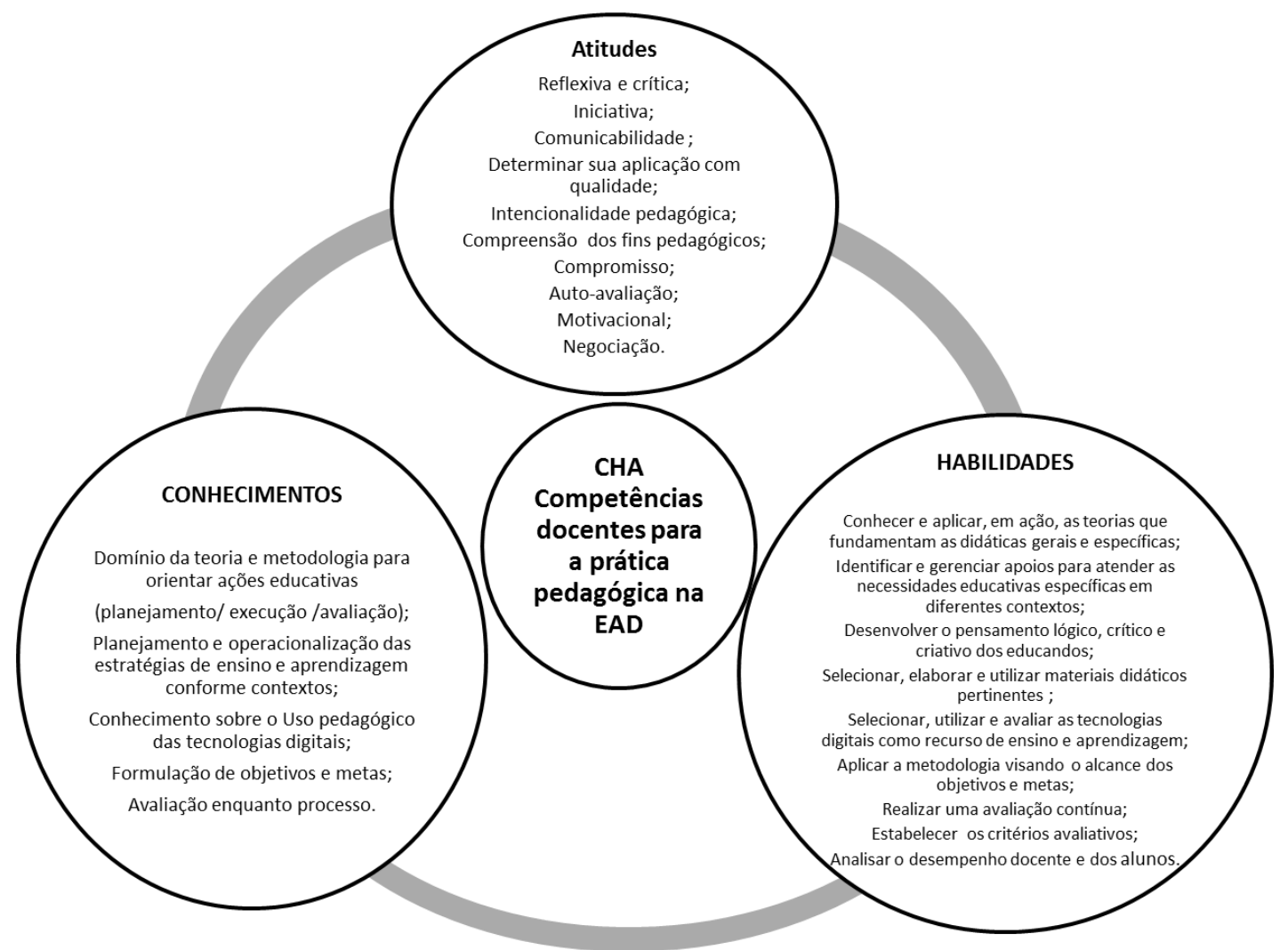

Figura 4.2. Competências docentes para a EAD - Adaptado [Bernardi et al. 2013, p.191]

Dentre os Conhecimentos evidenciados, está o domínio da teoria e metodologia a fim de orientar as ações educativas, através da elaboração de um planejamento, a sua execução e avaliação. Ressalta-se, neste sentido, a importância de definir objetivos e metas, além de se levar em conta o contexto da atividade pedagógica, o perfil da turma (e seu conhecimento tecnológico) e as tecnologias disponíveis para a definição das metodologias e estratégias de aprendizagem a serem empregadas.

Quanto às Habilidades, cabe ao professor o conhecimento das teorias basilares para as didáticas gerais e específicas para aplicá-las de forma coerente, em sintonia com as necessidades educativas específicas dos seus alunos e dos diferentes contextos de ensino e aprendizagem. Além disso, é preciso realizar a seleção dos materiais didáticos e das tecnologias digitais a serem utilizadas como recursos de ensino, em convergência com as metodologias selecionadas a fim de alcançar os objetivos propostos. Todas estas decisões somadas compõe seu modelo pedagógico que poderá auxiliar no desenvolvimento do pensamento lógico, crítico e criativo dos alunos. Todas essas ações devem ser acompanhadas de uma avaliação contínua a partir do estabelecimento de critérios que permitam analisar o desempenho docente e discente. 
Com relação às Atitudes, espera-se uma postura reflexiva e crítica do professor, que busca assumir um compromisso e uma intencionalidade pedagógica na execução do trabalho docente. É através de sua iniciativa que o professor exerce uma ação motivacional para com seus alunos a fim de realizar a negociação visando a compreensão dos fins pedagógicos da prática educativa. Desta forma, o professor desempenha uma função mediadora e articuladora, aplicando os princípios de comunicabilidade e promovendo uma atividade de auto-avaliação com seus alunos.

A partir deste quadro, são evidenciados alguns dos Conhecimentos, Habilidades e Atitudes relacionados à ação didática e pedagógica do professor na EAD. Entende-se, entretanto que, em meio a cada um desses conhecimentos, outros aspectos poderão ser enfatizados e detalhados, dependendo, assim, do modelo pedagógico de cada professor.

Neste sentido, o ensino baseado na construção das competências está sendo considerado como uma possibilidade de atender às demandas educacionais e identidade de cada professor.

\subsection{Práticas Pedagógicas}

O contexto apresentado até o momento tem focado sua abordagem nas competências docentes, ressaltando a relevância do planejamento pedagógico e sua aplicação nas salas de aula.

Quanto a este aspecto, tem-se observado que a utilização das tecnologias digitais da estão reforçando a necessidade de transformações nas metodologias educacionais das práticas pedagógicas na modalidade a distância. Estas mudanças solicitam um repensar da construção compartilhada de saberes com o uso de ferramentas digitais [Bernardi et al. 2013].

Logo, pretende-se abordar nesta seção, possíveis uso de ferramentas e recursos digitais nas práticas pedagógicas na EAD.

Conforme [Carlini e Tarcia 2010] o planejamento de atividades EAD pressupõe uma seleção de recursos pelo professor que venham atender as características de seu trabalho e também dessa modalidade. O grande desafio é criar condições para a aprendizagem, garantindo uma harmonização entre os elementos constituintes do planejamento.

A organização didática deve explicitar a relação construída pelo professor entre o uso das ferramentas e os objetivos previamente estabelecidos, desencadeando a articulação entre as partes do planejamento. De acordo com as autoras, o processo de planejamento pode ser organizado pelas questões: "A quem ensinar? Por que ensinar? O que ensinar? Como ensinar? e Que recursos usar?" [Carlini e Tarcia 2010, p. 43].

A questão "a quem ensinar?" deve obter como resposta, as informações relativas ao perfil dos alunos, definindo algumas das suas características, como, por exemplo, o atendimento dos aspectos relacionados à inclusão.

O "por que ensinar?" tem relação direta com os objetivos de ensino. São eles que estabelecem a visão acerca das transformações desejadas. Por isso os objetivos devem ser claros e relacionados aos saberes necessários a serem trabalhados com os alunos [Carlini e Tarcia 2010]. 
A questão sobre "o que ensinar?" diz respeito aos conteúdos da aprendizagem. Nesta perspectiva, o trabalho do professor não deve se limitar aos saberes teóricos e disciplinares, buscando "re-signifcar tais conhecimentos no sentido de avaliar suas contribuições efetivas para a concretização dos objetivos" [Carlini e Tarcia 2010, p. 45].

As ações de motivação empregadas pelo professor fazem referência à pergunta "como ensinar?". E nesse contexto, o uso das tecnologias, somadas às orientações didáticas visam provocar a compreensão acerca da atividade, seja esta individual ou coletiva.

A questão sobre "que recursos usar?" também faz parte do processo de planejamento. Sobre esta questão é ressaltada a necessidade do professor ter cuidado na seleção, integração e uso das tecnologias para a realização das atividades. O uso de materiais como textos, vídeos, fotos, imagens, esquemas devem ter a finalidade de agregar informações para os procedimentos metodológicos adotados e também oportunizar recursos diferenciados para contemplar os princípios de inclusão digital. $\mathrm{Na}$ Tabela 4.2 busca-se sintetizar a relação entre as questões do planejamento e os conhecimentos, habilidades e atitudes (CHA) das competências docentes no domínio pedagógica.

Tabela 4.2. Levantamento do CHA à luz das questões do planejamento pedagógico

\begin{tabular}{|c|c|c|c|}
\hline $\begin{array}{c}\text { Questões do } \\
\text { planejamento }\end{array}$ & CONHECIMENTOS & HABILIDADES & ATITUDES \\
\hline $\begin{array}{l}\text { "A quem } \\
\text { ensinar?" }\end{array}$ & $\begin{array}{l}\text { Levantamento do perfil dos } \\
\text { alunos, suas histórias de vida e } \\
\text { características da turma. }\end{array}$ & $\begin{array}{l}\text { Desenvolver atividades para } \\
\text { obter informações sobre perfil } \\
\text { dos alunos, para a definição } \\
\text { das características da turma. }\end{array}$ & $\begin{array}{c}\text { Atitude reflexiva e } \\
\text { crítica } \\
\text { Iniciativa }\end{array}$ \\
\hline $\begin{array}{l}\text { "Por que } \\
\text { ensinar?" }\end{array}$ & Formulação de objetivos e metas. & $\begin{array}{l}\text { Aplicar a metodologia visando } \\
\text { o alcance dos objetivos e } \\
\text { metas. }\end{array}$ & $\begin{array}{l}\text { Compreensão dos } \\
\text { fins pedagógicos }\end{array}$ \\
\hline $\begin{array}{c}\text { "O que } \\
\text { ensinar?" }\end{array}$ & $\begin{array}{l}\text { Domínio da teoria e metodologia } \\
\text { para orientar ações educativas } \\
\text { (planejamento/ execução } \\
\text { /desenvolvimento). }\end{array}$ & $\begin{array}{l}\text { Conhecer e aplicar, em ação, } \\
\text { as teorias que fundamentam as } \\
\text { didáticas gerais e específicas. }\end{array}$ & $\begin{array}{l}\text { Determinar sua } \\
\text { aplicação com } \\
\text { qualidade }\end{array}$ \\
\hline \multirow{2}{*}{$\begin{array}{l}\text { "Como } \\
\text { ensinar?" }\end{array}$} & $\begin{array}{l}\text { Planejamento e operacionalização } \\
\text { das estratégias de ensino e } \\
\text { aprendizagem conforme } \\
\text { contextos. }\end{array}$ & $\begin{array}{l}\text { Identificar e gerenciar apoios } \\
\text { para atender as necessidades } \\
\text { educativas específicas em } \\
\text { diferentes contextos; } \\
\text { Selecionar, elaborar e utilizar } \\
\text { materiais didáticos pertinentes. }\end{array}$ & $\begin{array}{c}\text { Intencionalidade } \\
\text { pedagógica }\end{array}$ \\
\hline & Avaliação enquanto processo. & $\begin{array}{l}\text { Realizar uma avaliação } \\
\text { contínua; } \\
\text { Estabelecer os critérios } \\
\text { avaliativos; } \\
\text { analisar o desempenho docente } \\
\text { e dos alunos. }\end{array}$ & Negociação \\
\hline
\end{tabular}

A partir das questões apresentadas por [Carlini e Tarcia 2010] na sequência busca-se evidenciar alguns recursos e tecnologias digitais que podem contribuir com o planejamento pedagógico e a realização de atividades na modalidade a distância dos seguintes níveis de ensino e públicos: Ensino Fundamental, Ensino Médio e Ensino Superior. 


\subsubsection{Ensino fundamental}

(1) Planeta ROODA: o Planeta ROODA (http://www.nuted.ufrgs.br/planeta2) (Figura 4.3) é um ambiente virtual de aprendizagem (AVA) voltado para a Educação Infantil e Ensino Fundamental. Possui diferentes funcionalidades, o que permite múltiplas práticas pedagógicas. Através deste AVA, o professor pode utilizar a funcionalidade Biblioteca, para disponibilizar arquivos, links e ou imagens para os alunos. Uma possível estratégia com esta funcionalidade é solicitar que os alunos realizem pesquisas e postem os resultados encontrados na Internet sobre temas que estão sendo trabalhados em sala de aula.

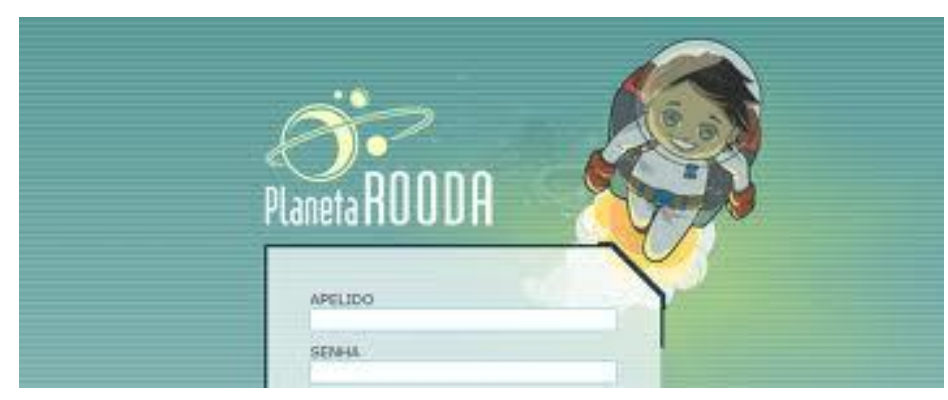

Figura 4.3. Planeta Rooda

(2) História em Quadrinhos: o uso de Histórias em Quadrinhos (HQ) é uma atividade motivadora e lúdica para a aprendizagem dos alunos. Uma ferramenta digital para desenvolver HQ é a Máquina de Quadrinhos da Turma da Mônica (http://www.maquinadequadrinhos.com.br/Intro.aspx) (Figura 4.4). Considera-se importante, dependendo da faixa etária das crianças, que o professor realize o cadastro juntamente com os alunos. Uma sugestão de tarefa é entregar um texto para os alunos e solicitar que os mesmos o representem em forma de HQ sem usar expressões textuais.

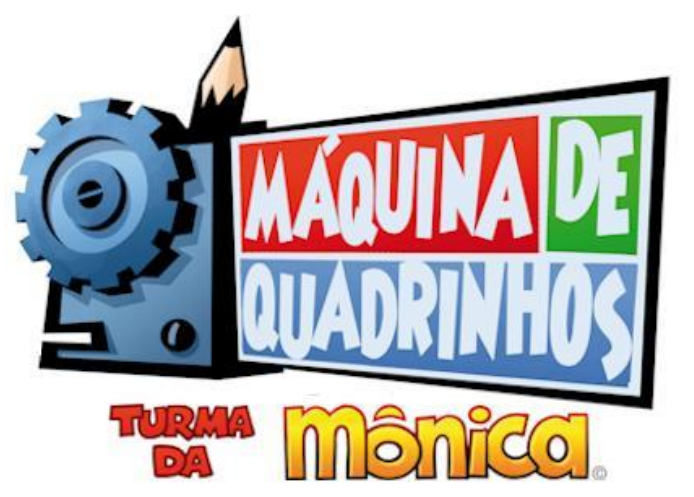

Figura 4.4. Máquina de Quadrinhos 


\subsubsection{Ensino médio}

(1) Álbum virtual: a ferramenta MixBook (http://www.mixbook.com) (Figura 4.5) permite a construção de álbuns com montagem de fotos e, imagens e textos, através da técnica do scrapbook, ou seja, álbum de recortes. Este recurso permite ao aluno a escolha do tipo de álbum. Trata-se de um excelente recurso para trabalhar de forma colaborativa. O professor pode solicitar que o aluno construa uma narrativa utilizando imagens como ilustração, ou mesmo que realize um resumo do conteúdo trabalhado.

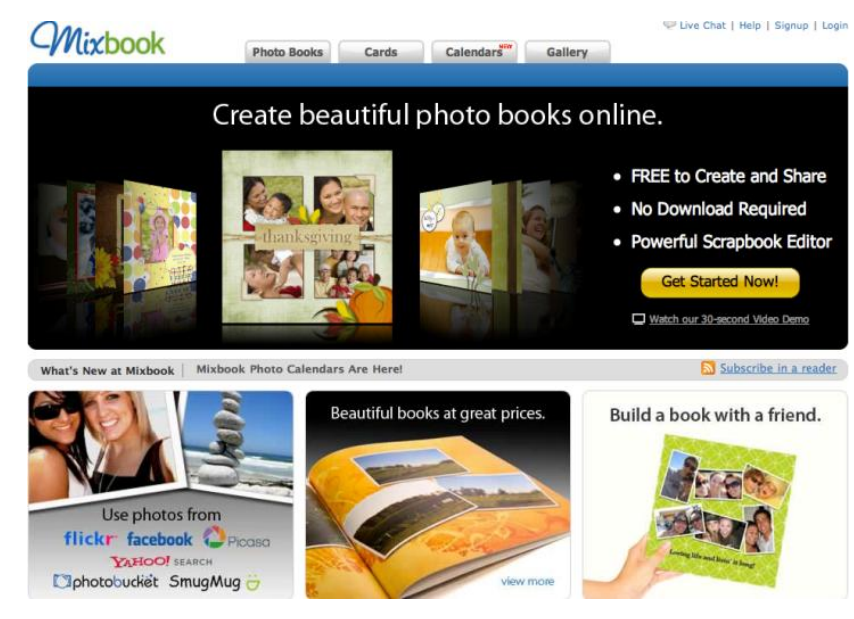

Figura 4.5. Mixbook

(2) Pôster digital: a construção de pôsteres virtuais pode ser realizada através da ferramenta Glogster (http://www.glogster.com/) (Figura 4.6). O software possui ricos recursos digitais, o que permite ao professor múltiplas atividades com os seus alunos. Como exemplo, pode solicitar que o aluno escolha um tema e imagine que este seja um produto no qual deverá realizar a propaganda para vender. Para realizar a publicidade do "produto", o aluno poderá construir um pôster virtual.

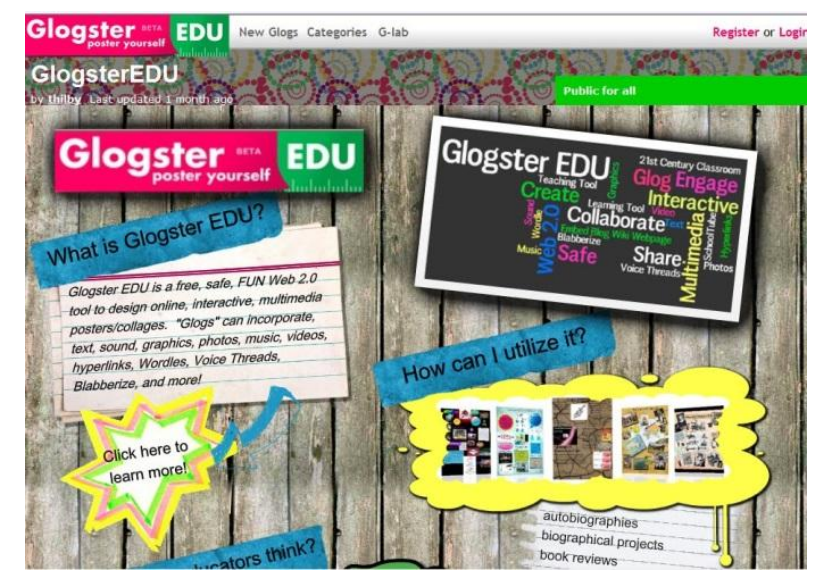

Figura 4.6. Glogster 


\subsubsection{Ensino superior}

(1) Rede social: Nos dois últimos anos cresceu o interesse no uso de redes sociais. Traz-se aqui a sugestão do recurso digital Crowdvine (http://www.crowdvine.com) (Figura 4.7). Nesta ferramenta o aluno deverá realizar um cadastro e escolher o plano free. Em seguida é possível montar o design, as discussões e convidar as pessoas para a discussão sobre o tema. É importante que o professor seja convidado como "organizador" do evento, assim terá todos os poderes de edição do site/rede social.

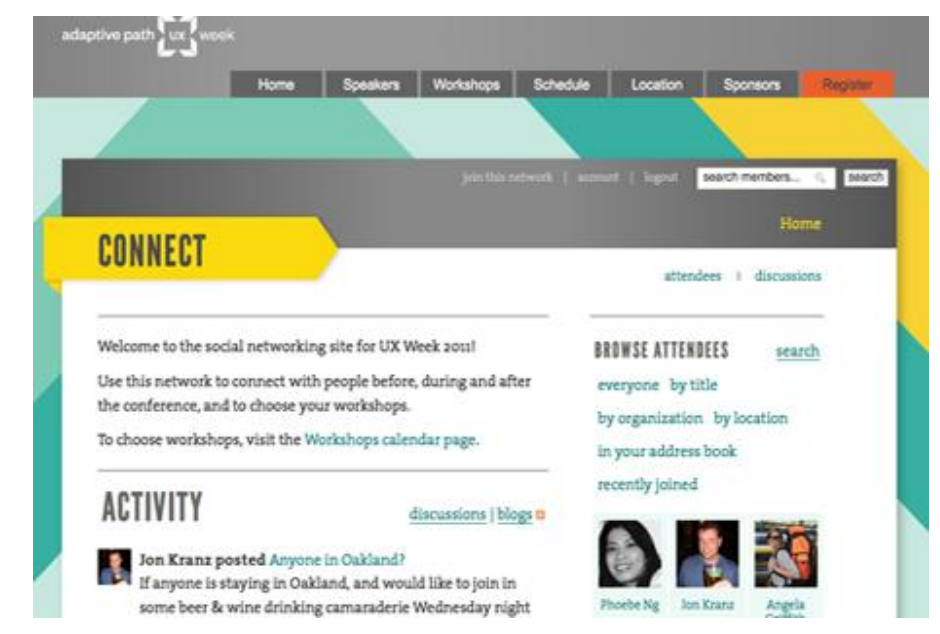

Figura 4.7. Crowdvine

(2) Noticias online: pode-se utilizar um recurso de criação de sites para a elaboração de um Jornal Online. A dica aqui é para o uso do site JEX (http://www.jex.com.br/pg_dinamica/bin/pg_dinamica.php) (Figura 4.8).

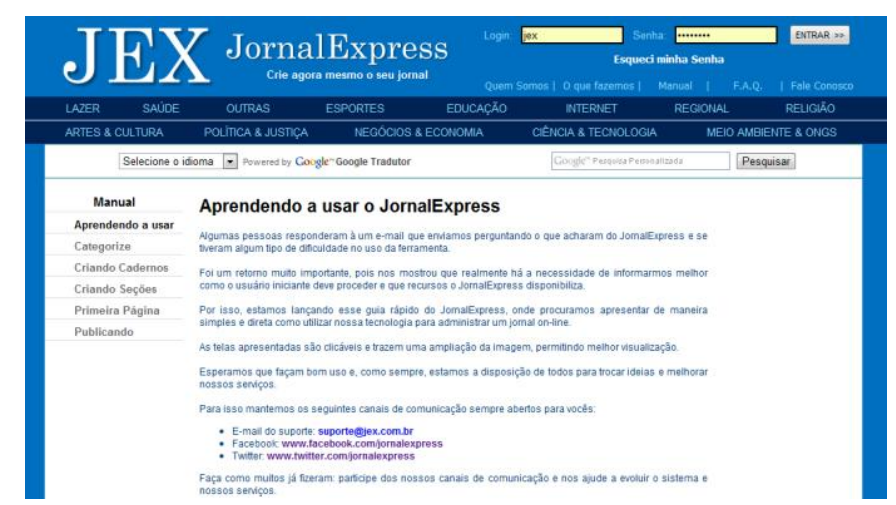

Figura 4.8. JEX JornalExpress 


\subsubsection{Idosos}

(1) Blog: O uso de Blogs é sugestão, já que permite o registro dos desafios e das conquistas durante a aprendizagem. Aconselha-se que o professor crie a conta do blog presencialmente, assim como a explicações no uso da ferramenta. Um recurso gratuito e de fácil uso para este público é o Blogger. (http://www.blogger.com/) (Figura 4.9).

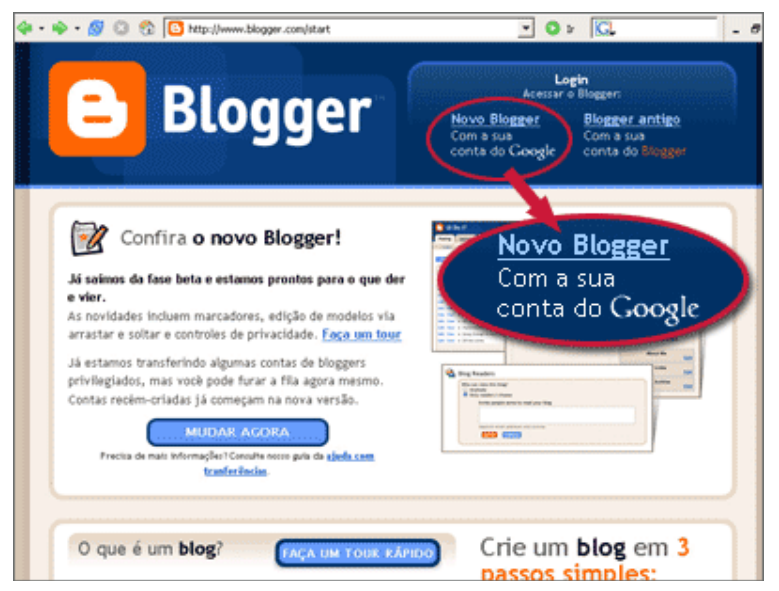

Figura 4.9. Blogger

(2) Livro digital/e-books: existem muitas ferramentas disponíveis para esta criação. uma delas é o recurso digital Issuu (disponível em http://www.issuu.com) (Figura 4.10). No e-book, o idoso pode escrever sobre fatos históricos e memórias passadas. $\mathrm{O}$ uso deste tipo de dado é relevante e motivador na autoanálise a autoavaliação sobre a vida. Pode-se utilizar imagens e fotos para complementar o livro.
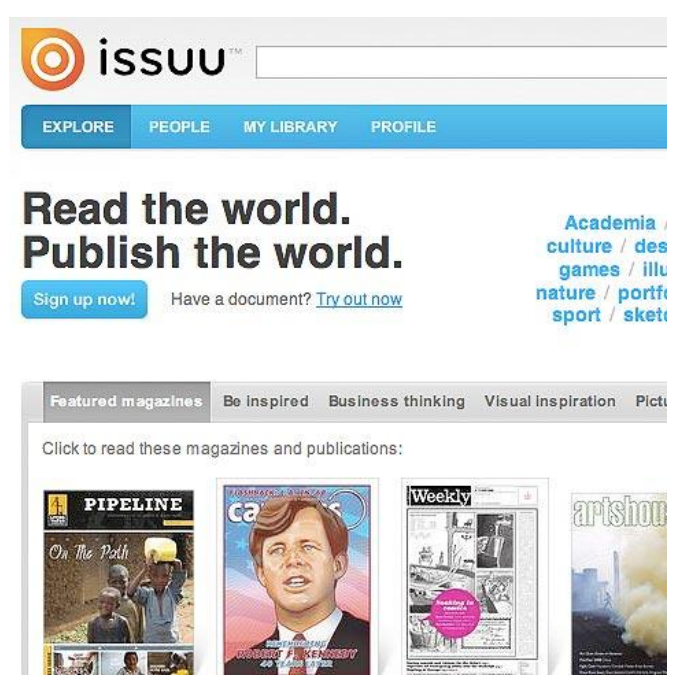

Figura 4.10 - Issuu 


\subsubsection{Alunos com necessidades especiais}

(1) Falador: O software Falador (Figura 4.11) é um programa que converte texto para voz, o que permite múltiplas atividades (http://www.baixaki.com.br/download/falador.htm). Uma opção é a disponibilização de texto sobre qualquer tema e a solicitação de ilustração deste tema ou do que entendeu do texto falado. O professor, por exemplo, pode solicitar que o aluno leia um texto sobre o uso das TIC na Educação, como o do Moran: "A integração das tecnologias na educação" (http://www.eca.usp.br/moran/textos.htm). Após a leitura o aluno pode representar em forma de imagem o que entendeu da leitura. Para a criação da imagem, pode ser utilizado o ArtPad (http://artpad.art.com/artpad/painter/). Nesta ferramenta é possível salvar ou enviar para quem quiser a imagem criada.

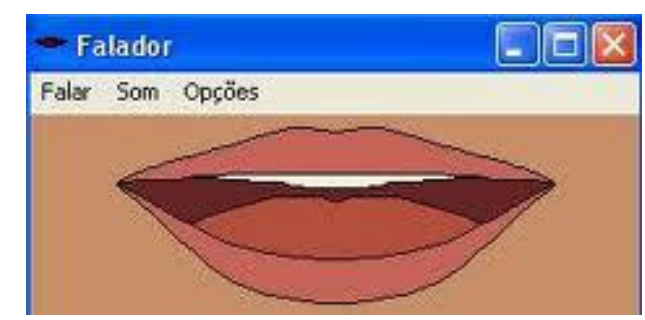

Figura 4.11. Falador

(2) Prancha Livre de Comunicação: existe um software gratuito para criação de Pranchas de Comunicação que é a "Prancha Livre de Comunicação" (http://www.ler.pucpr.br/amplisoft/) (Figura 4.12). O professor pode solicitar que o aluno construa a sua prancha de comunicação com os símbolos disponibilizados e depois compartilhe com os colegas e com o próprio educador.

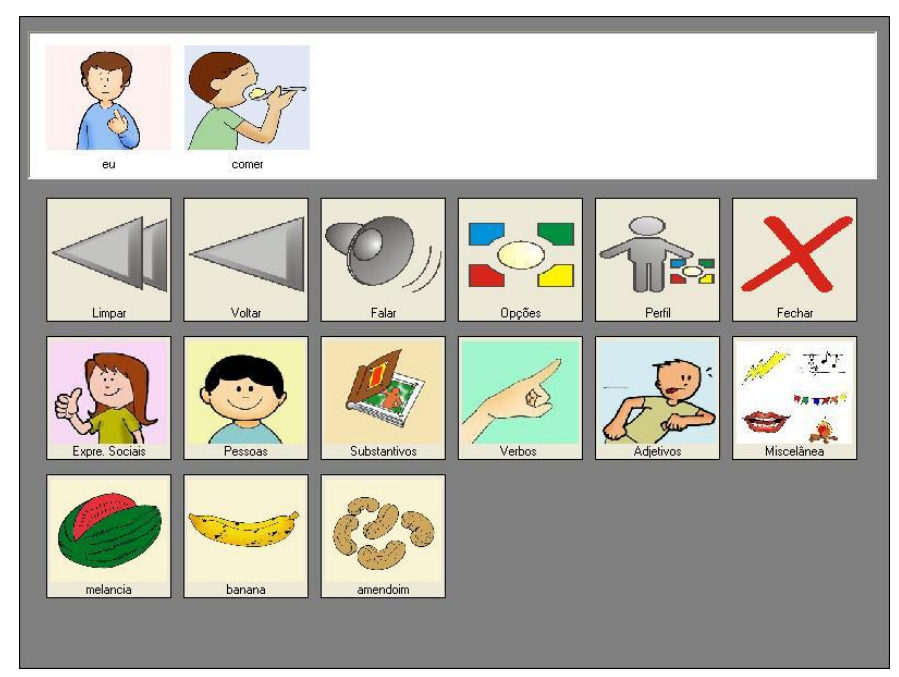

Figura 4.12. Prancha Livre de Comunicação 


\subsection{Finalizando}

A Educação a Distância exige um olhar diferenciado e cuidadoso por parte do professor. Atualmente, depara-se com diversos modelos pedagógicos centrados apenas no ato de ensinar e no mecanicismo. Essas práticas enfraquecem as potencialidades que a modalidade é capaz de favorecer.

Atrelado a isso estão as competências do professor, pois é sob a sua prática que a EAD é impulsionada e motivada. Logo, torna-se necessário mobilizar tais competências para que o professor tenha subsídios suficientes para sua atuação, visando atingir o objetivo de favorecer o processo de construção do conhecimento por parte do seu aluno.

Dessa forma, o professor poderá promover a elaboração de um planejamento pedagógico adequado, tendo em vista o seu público alvo e seus objetivos educacionais.

Com a utilização das tecnologias digitais e a mobilização de tais competências o professor potencializará a função de mediador da aprendizagem e poderá transcender as práticas tradicionais tão comuns na educação.

\section{Referências}

Behar, P. A. (2013) “Competências em educação a distância”. Porto Alegre: Penso.

Bernardi, M.; Moresco, S. F. da S.; Behar, P. (2013) Competências para a prática pedagógica na educação a distância: uma análise a partir do modelo pedagógico. In: Behar, P. A. (2013) "Competências em educação a distância”. Porto Alegre: Penso.

Carlini, A.; Tarcia, R. M. (2010) “20\% a distância: e agora?: Orientações práticas para o uso de tecnologia de educação a distância". São Paulo: Pearson Education do Brasil, p.177.

Coronado, M. (2009). "Competências Docentes - ampliação, enriquecimento e consolidação da prática profissional". Buenos Aires: Centro de Publicaciones Educativas Y Material Didáctico.

Dolle, J.M. (1993) "Para além de Freud a Piaget: referenciais para novas perspectivas em psicologia”. Petrópolis, RJ: Vozes.

Freire, P. (1996). "Pedagogia da Autonomia: Saberes Necessários à Prática Educativa". São Paulo: Paz e Terra.

Nevado, R. A. de; Menezes, C. S. de; Carvalho, M. J. S. (orgs.) (2007). “Aprendizagem em rede na educação a distância: estudos e recursos para formação de professores". Porto Alegre: Ricardo Lenz.

Paquay, L. e Wagner, M. C. (2001). "Competências profissionais privilegiadas nos estágios e na videoformação". In: P. Perrenoud, et al (org.), Formando professores profissionais: quais estratégias? quais competências?. $2^{\mathrm{a}}$ ed., Porto Alegre, Artmed, p. $135-159$.

Perrenoud, P. et al. (2002) "As competências para ensinar no século XXI: a formação dos professores e o desafio da avaliação". Porto Alegre: Artmed.

Perrenoud, P. (2001) "Porquê construir competências a partir da escola? Desenvolvimento da autonomia e luta contra as desigualdades". Porto: ASA.

Rodrigues, A. S. S. (1994) "Psicologia social”. Petrópolis: Vozes. 
II Congresso Brasileiro de Informática na Educação (CBIE 2013)

II Jornada de Atualização em Informática na Educação (JAIE 2013)

Zaballa, A.; Arnau, L. (2010) "Como aprender e ensinar competências: uma proposta para o currículo escolar”. Porto Alegre: Artmed. 